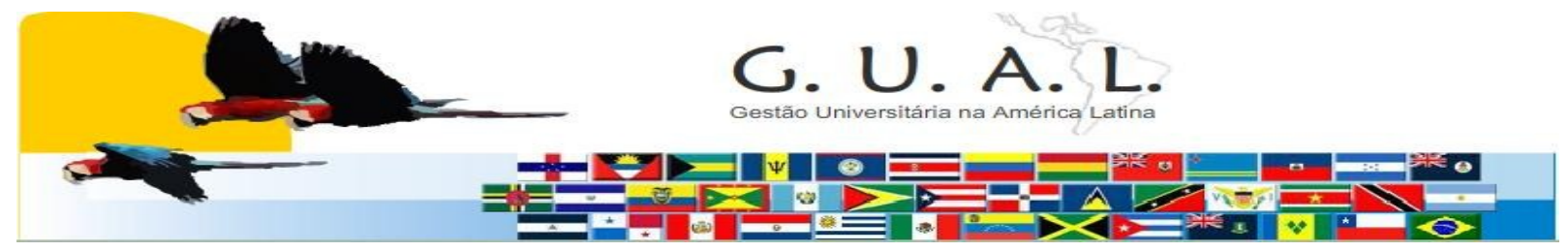

ISSN 1983-4535

\title{
AS CONTINGÊNCIAS HISTÓRICAS E O ENSAIO PRECOCE DO QUE SE CONSOLIDARIA COMO O PROCESSO DE INTERNACIONALIZAÇÃO DA UFSC
}

\author{
Sonia Pereira Laus, Mestre \\ Universidade do Estado de Santa Catarina - UDESC \\ sonia.laus@udesc.br
}

\section{RESUMO}

O presente artigo apresenta uma visão geral do processo de internacionalização da Universidade Federal de Santa Catarina, com foco nas atividades desenvolvidas nos anos 1960/1970 pelo curso de pós-graduação em Administração Universitária em colaboração, principalmente com instituições latino-americanas, e tendo por fator desencadeador os acordos MEC/USAID. O estudo relaciona ainda os principais rankings acadêmicos internacionais e seus elementos de avaliação, com ênfase no Ranking Mundial de Universidades na WEB, o Webometrics e no Ranking Ibero-Americano de Produção Científica e Internacional, ressaltando a posição da UFSC nos mesmos, concluindo com uma crítica à homogeneização proposta pelos indicadores de internacionalização ora adotada pelos organismos internacionais e pela CAPES.

Palavras-chave: Pós- Graduação. Universidade. Internacionalização. Rankings acadêmicos. 


\section{INTRODUÇÃO}

Com sua sede em Florianópolis, capital do Estado de Santa Catarina, em termos numéricos a Universidade federal de Santa Catarina (UFSC) é hoje a terceira maior universidade do Brasil e a quinta da América Latina. No ano de 2010 possuía 57 Departamentos e duas Coordenadorias Especiais que integravam 11 Unidades Universitárias onde eram oferecidos 39 Cursos de Graduação com 52 Habilitações, nos quais estavam matriculados 22.908 alunos em cursos presenciais e 5.105 nos de Educação a Distância.

Oferecia ainda 57 programas de pós-graduação stricto sensu, dez deles considerados como com "desempenho equivalente ao dos centros internacionais de excelência na área", pelos critérios da avaliação trienal 2007-2009 da CAPES, constituídos por 44 Doutorados e 56 Mestrados, com um total de 5.357 alunos e 88 de pós-graduação lato sensu, com 8.233 alunos. Os referidos cursos são oferecidos em sua sede, em Florianópolis e nos campi de Joinville, Curitibanos e Araranguá, perfazendo um total de 41.693 alunos.

Sua estrutura acadêmica é composta ainda por 514 grupos de pesquisa cadastrados no CNPq, nos quais atuam 3.146 pesquisadores, 5.512 estudantes e 468 técnicos, num total de 2.031 linhas de pesquisas. Dentre os docentes, cerca de $87 \%$ possuem formação de doutor sendo que $24,2 \%$ destes eram, naquele ano, bolsistas em produtividade do CNPq, observandose que $100 \%$ dos Pesquisadores Seniores da citada agência governamental e $84 \%$ dos 473 bolsistas de produtividade do Estado de Santa Catarina estão concentrados na UFSC.

Entendendo a internacionalização de uma universidade como o processo de diálogo (trabalhos conjuntos, cooperação, intercâmbio, adequação das estruturas institucionais, conflitos e problemas surgidos) com outras universidades ou organizações variadas (empresas, governos, agências internacionais, ONGs) do mundo exterior à fronteira nacional na concepção, desenvolvimento ou implementação de suas funções de ensino, pesquisa e extensão, nossa hipótese é que o processo de internacionalização da UFSC ocorre em paralelo à consolidação de seus programas de pós-graduação.

Corroborado pela citada mais recente avaliação da CAPES e pelos rankings acadêmicos internacionais, esse processo teve sua gênese, por contingências históricas, quase que em paralelo ao processo de criação da UFSC, nos anos 1960, conforme analisaremos a seguir.

Rev. GUAL., Florianópolis, Edição especial 2011, p.208-226. 


\section{OS ACORDOS MEC/USAID E OS CAMINHOS PARA A INTERNACIONALIZAÇÃO}

Com base nos acordos MEC/USAID, um conjunto de acordos assinados pelo governo do Brasil com a Agência dos EUA para o Desenvolvimento Internacional, do inglês United States Agency for International Development, entre os anos de 1964 e 1968, sendo alguns com vigência até o ano de 1971, o país receberia apoio técnico e financeiro para a elaboração das reformas em setores considerados pouco estruturados para dar suporte ao seu processo de desenvolvimento.

No período foi assinado um total de 12 acordos entre o governo brasileiro e aquela agência, sem contar aqueles firmados com os governos estaduais. Entre os estabelecidos com o Ministério da Educação e Cultura, o de 30 de junho de 1966 referia-se a educação superior: o Acordo MEC/USAID de Assessoria para a Modernização da Administração Universitária. Frente à reação geral do meio acadêmico, receoso à ingerência norte-americana em assuntos do interesse nacional, o documento foi revisado 10 meses depois e substituído por outro objetivando a Assessoria do Planejamento do Ensino Superior, vigente até 30 de junho de 1969 (ROMANELLI, 1998).

No âmbito desse documento, o Brasil receberia apoio técnico e financeiro para a implantação das reformas entendidas como necessárias para um país que desde os ciclos econômicos do período colonial vinha se integrando ao capitalismo internacional, mesmo que de forma subordinada e paulatinamente desvinculava-se das oligarquias tradicionais inserindo-se no universo desenvolvimentista, no qual os Estados Unidos da América apresentava-se como modelo acabado a ser difundido principalmente para o mundo chamado "subdesenvolvido".

Nesse sentido, a conseqüente ênfase na profissionalização presente na legislação que norteou a educação nacional a partir dessa época refletiria a necessidade de preparação de quadros considerados aptos para atuarem junto ao crescente empresariado que vinha assumindo o controle econômico do país e dando suporte ao governo militar instalado em 1964.

Nesse contexto, a chamada Reforma Universitária foi então sugerida pelos documentos elaborados pelos especialistas contratados, entre os quais se destacava Rudolph Atcon, membro da USAID, com estudos anteriores sobre universidades da América Latina e que durante a assinatura dos primeiros acordos com o MEC orientou os programas e 
apresentou sua proposta, na publicação intitulada Rumos à Reformulação Estrutural da Universidade Brasileira (1966), também conhecido como Relatório Atcon. Promovida pelo MEC, com as conclusões do estudo contratado que obviamente tinha em mente o modelo universitário norte-americano, as conclusões alicerçavam-se "em princípios de economia e produtividade bem próprios da mentalidade empresarial" (ROMANELI, 1998, p. 127), propondo a redução de custos, pela otimização de recursos humanos e materiais bem como de espaços físicos.

Suas diretrizes foram regulamentadas pelos Decretos Lei n. ${ }^{\circ}$ 53, de novembro de 1966 e $n^{\circ} 252$ de fevereiro de 1967, que, entre outras mudanças nas universidades brasileiras, determinam a extinção das cátedras e das faculdades e a criação do sistema de créditos, do ciclo básico e dos centros, por áreas de conhecimento, divididos em departamentos. Ressaltese que as reformas refletiam a fina sintonia entre a educação e a ideologia de desenvolvimento com segurança defendida pela coligação dos vários grupos que davam sustentação política ao poder naquele momento: de um lado, os conservadores já citados, representados pelas classes dominantes (banqueiros, comerciantes, industriais e também os latifundiários), segmentos da igreja católica e representantes da nova classe media que aspirava conquistas sociais. Do outro, respaldando-lhes, os grupos internacionais que atuavam na política e na economia do país.

Observe-se ainda que nas conclusões do referido estudo estava a criação de um Conselho de Reitores das Universidades Brasileiras e a organização de sua Secretaria Geral, para controle interno das universidades e independente do Poder Executivo "nos moldes empresariais, para criar um local ecologicamente (sic) apropriado para empreender estudos sistemáticos sobre o ensino superior e planejamento ininterrupto”( ATCON, 1966, p.121). O protagonismo da UFSC nesse processo ocorre pelo fato de, em meio às visitas técnicas dos consultores norte-americanos às universidades brasileiras, ter recebido, no final da década de 1960, a visita de Rudolph Atcon, que, nas citadas conclusões de seu relatório a aponta e à sua reitoria como modelos para uma gestão acadêmica moderna.

Tudo isso, em si, não representaria mais do que o quadro de uma pequena e nova Universidade tradicional em desenvolvimento. O que a transforma em um local promissor é, por um lado, a orientação que lhe proporciona o Reitor e os seus colaboradores, e, por outro lado, a grande novidade que ali encontrei no que diz respeito a um sistema administrativo verdadeiramente

Rev. GUAL., Florianópolis, Edição especial 2011, p.208-226. 
modelar. Em Florianópolis encontrei a solução administrativa para as universidades brasileiras. (ATCON, 1966, p. 69,70)

Lembrando-nos de que no final dos anos 1960 estão os primórdios da aplicação das nascentes tecnologias de informação e comunicação à gestão, Atcon referia-se principalmente ao uso adequado e eficiente de uma moderna mecanização administrativa, com o uso "de umas tantas novas máquinas", tendo como conseqüência o fato de que "todo o processo que entra na Universidade ou se origina nela é atendido com rapidez, sem as tão desnecessárias duplicações de trabalho", onde documentos e questões de ordem financeira são tratados com a eficiência só encontrada "em boas empresas privadas e quase nunca no serviço público" (ibid. p. 70), mesmo "numa realidade vigente de uma administração universitária ainda ligada aos cânones do DASP"1 (ibid. p.71). O entusiasmo do consultor com a eficiência administrativa ali verificada o leva a recomendar em seu estudo

"a aplicação do sistema mecanizado de administração central da Universidade Federal de Santa Catarina a todas as outras universidades do país, com a aquisição das mesmas máquinas [...] e o adestramento de seus funcionários administrativos em Florianópolis" (ibid. p.123)

Se tivermos em conta as características do poder brando, do inglês soft power amplamente utilizado pela USAID, que se caracteriza pela habilidade de seduzir os outros para obter os resultados que se quer através da atração mais do que da coerção ou pagamento ${ }^{2}$, corroboradas pelo que aponta Romanelli (1998) que uma das características fundamentais da atuação da USAID era aquela que implicava doutrinação e treinamento de órgãos e pessoas intermediários com vistas a uma intervenção na formulação das estratégias pretendidas pela agência, transferindo a responsabilidade quanto à opção e implantação dos programas a esses agentes nacionais "motivados", como sendo viável apenas "em situações de dependência em que o setor interno se predispõe não apenas a aceitar os programas de reformulação do sistema educacional, mas também a trabalhar e responsabilizar-se por sua execução" (op.cit. p.210), podemos observar tanto na criação do Conselho de Reitores das Universidades Brasileiras ( CRUB) quanto nas ações desenvolvidas na UFSC a concretização dessas premissas.

\footnotetext{
${ }^{1}$ DASP, Departamento Administrativo do Serviço Público, criado pelo Decreto Lei No579 de 30/07/1938, diretamente subordinado à Presidência da República, foi o responsável pela profissionalização da carreira do servidor público.

${ }^{2}$ NYE, 2004
}

Rev. GUAL., Florianópolis, Edição especial 2011, p.208-226. 
Corroborando essa afirmação, e como fruto da recomendação do relatório Atcom, em abril de 1966, durante o VII Fórum Universitário, realizado no Rio de Janeiro, os reitores de 28 universidades brasileiras se responsabilizaram pela redação do documento de criação do CRUB. Logo de sua criação, o referido Conselho ficou responsável pela execução do citado Acordo MEC/USAID, investindo na contratação de especialistas estrangeiros em gestão universitária, na promoção de treinamentos fora do país e na distribuição de material impresso aos dirigentes universitários ${ }^{3}$.

Ainda corroborando a afirmação da autora citada, em junho de 1967, mesmo ano em que o seu reitor, João David Ferreira Lima, fora eleito o segundo Presidente do recém criado CRUB, foi aprovado pelo Conselho Universitário da UFSC um convênio com aquela entidade $^{4}$ para a realização de um Curso de Treinamento e Aperfeiçoamento em Administração Universitária. Custeado por um repasse de Cr\$400.000,00 feitos pelo MEC, o curso estruturou-se sob a forma de um ciclo de estudos, com encontros de grupos de diretores e técnicos de administração universitária de IES de todo o país, inclusive católicas, particulares e estaduais.

Alinhada às políticas do governo federal referentes à Reforma Universitária e uma das primeiras a implantá-la e ainda em decorrência do exitoso curso iniciado em 1968, a UFSC recebe a visita de reitores de América Central bem como do Secretário Geral da Fundação de Universidades Privadas da América Central (FUPAC), composta por instituições da Guatemala, Honduras, Nicarágua, El Salvador, Costa Rica e Panamá, propondo um convênio para a oferta do referido curso a seus técnicos além de assessoria às reformas a serem implantadas nas universidades daquela região.

Frutos de tal negociação, os novos cursos passaram a ser ofertados na UFSC, com a duração de 30 dias, a grupos daqueles países, acrescidos por representantes do México e da República Dominicana que aderem à FUPAC para usufruir do convênio (LIMA, 2000).

No ano de 1971, visando avaliar essa sua experiência latino-americana, a UFSC realizou o seu primeiro evento internacional, o Seminário Internacional de Administração

\footnotetext{
${ }^{3}$ Disponível em: http://www.crub.org.br/interna.php?id=9. Consulta em: 27 maio 2011.

${ }^{4}$ Observe-se que em paralelo ao convênio com a UFSC, o então presidente do CRUB assina convênio com a Universidade de Houston, no Texas para o treinamento de administradores das IES brasileiras naquele país, por períodos de 30 dias, bem como a recepção de seus técnicos para treinamento local em nossas IES (UFSC, 1971)
}

Rev. GUAL., Florianópolis, Edição especial 2011, p.208-226. 
Universitária $^{5}$ ao qual compareceram 45 universidades, sendo 23 brasileiras e 22 estrangeiras e 137 delegados de 14 países, sendo 13 da América Latina e um da Alemanha. Num momento de forte envolvimento da educação brasileira com organizações internacionais como o Banco Interamericano de Desenvolvimento (BID), a já mencionada USAID, e a Organização dos Estados Americanos (OEA), essas agências, bem como e recém-criada União das Universidades da América Latina (UDUAL), enviaram representantes ao evento, cuja preparação trouxe melhorias infraestruturais para o campus, como a conclusão do prédio da reitoria e seu auditório, bem como a instalação de serviços como correios e agência bancária.

Exemplo acabado do leque de relações internacionais que embasavam a Reforma Universitária no país, o evento sinaliza a abertura aos diálogos internacionais, principalmente àqueles já iniciados com a América Latina, traz prestígio à UFSC ao mesmo tempo em que abre as portas para a ampliação de suas relações institucionais fora das fronteiras do país.

O formato de ofertas de seminários abertos à participação internacional seguiria até o ano de 1978, quando foi criado o curso de pós-graduação em Administração com área de concentração em Gestão Universitária, ainda atendendo a uma clientela nacional e latino americana. Ministrado em português e espanhol, o curso recebia alunos brasileiros com bolsas da CAPES e CNPq e latino-americanos, com bolsas do BID (VAHL, 2011). Nos anos 1980, as atividades pregressas do curso e sua visibilidade em âmbito latino-americano credenciam a UFSC a mais um avanço na ampliação de suas relações acadêmicas internacionais.

Conforme o entrevistado citado, no Seminário de criação da Organização Universitária Inter- Americana (OUI), em 1980, a IES apresentou sua expertise, num informe sobre os seminários e o curso de pós-graduação em gestão universitária que vinha oferecendo no Brasil, o que levou os filiados da recém criada organização com sede no Canadá e que congrega universidades das Américas do Norte, Central e do Sul a solicitarem que ela se engajasse na sua oferta aos seus membros. Iniciam-se aí as negociações e em 1983 a OUI propôs a criação de um Instituto de Gestão e Liderança Universitário (IGLU) ${ }^{6}$, para a oferta de cursos de especialização em Administração Universitária às suas instituições associadas, os quais, com base no acordo de cooperação assinado entre a OUI e o CRUB, seriam realizados

\footnotetext{
5 O Seminário se realizou entre 26 de setembro e 2 de outubro. LIMA, 2000.

${ }^{6}$ Até a criação formal de um Instituto, com estrutura central, no Canadá e regional, com seis centros na América Latina e Caribe, o que só ocorrerá em 1996/1997, a sigla IGLU designava exclusivamente os cursos e seminários oferecidos.
}

Rev. GUAL., Florianópolis, Edição especial 2011, p.208-226. 
no Brasil e ministrados pela $\operatorname{UFSC}^{7}$, seguidos de um estágio prático e de visitas às universidades dos EUA e do Canadá.

Tais estágios eram financiados pela OEA e pela Agência Canadense para o Desenvolvimento Internacional (ACDI/CIDA), até que em finais dos anos 1980 a OEA retira seu apoio ao programa, inviabilizando os estágios nos EUA, permanecendo a ACDI como única apoiadora aos estágios, a partir daí somente realizados no Canadá. O que se pode observar é que o fluxo ininterrupto de recepção de dirigentes e funcionários da alta administração de instituições de toda a América Latina bem como das diversas regiões do Brasil, ampliaram ainda mais a visibilidade institucional da UFSC e sua capacidade de diálogo internacional iniciada no final dos anos 1960, caracterizando aquilo que entendemos como um ensaio precoce do que seria seu processo de internacionalização que ganha contornos mais técnicos, incorporando-se à missão, visão, valores e ao planejamento estratégico da universidade a partir do final dos anos 2000.

Daquele episódio protagonizado pelo curso de pós-graduação em gestão universitária embora, por decisão do CRUB, o convênio com a UFSC tenha sido rescindido em 1989, passando os cursos de Gestão e Liderança Universitária a ser itinerantes a partir de 1990, realizando-se sob sua supervisão em diversas cidades brasileiras e ministrados por professores convidados, o ciclo volta a fechar-se no ano 2011. Por negociação proposta pela OUI, a UFSC reassume a oferta dos cursos no país, passando a constituir-se na sede do Centro IGLU Brasil.

\subsection{A Pós- Graduação na UFSC nasce internacional}

Em paralelo às atividades relatadas e seguindo a política de indução de formação pósgraduada promovida pelo governo federal nos anos 1970, a UFSC desenvolveu uma política agressiva de formação de seus docentes. No ano de 1979, 28,7\% dos 1.278 docentes estavam cursando especialização, mestrado e doutorado sendo que, dos 65 professores afastados para doutorado, 46 estavam no exterior.

Seu primeiro curso de Mestrado, o Curso de Pós-Graduação em Engenharia Mecânica (CPGEM) iniciou suas atividades em março de 1969, com professores visitantes estrangeiros (Tcheco-Eslováquia, China, Finlândia e França) e se fortalece principalmente com o convênio

\footnotetext{
${ }^{7}$ Em seu primeiro ano, 1984, com o assentimento do CRUB, o curso foi oferecido pela Fundação Getúlio Vargas, do Rio de Janeiro, que recebeu os participantes hispano-americanos, mas a partir de 1985 passa a ser oferecido pela UFSC.
}

Rev. GUAL., Florianópolis, Edição especial 2011, p.208-226. 
firmado em 1976 entre a UFSC e a Rheinisch Westfälische Tecchnische Hochschule ${ }^{8}$, da Alemanha, entre outros firmados com o mesmo país e com a França e Holanda, entre outros.

O Mestrado em Engenharia Elétrica foi criado em 1971 e outros cursos de pósgraduação funcionavam desde os anos 1970, como por exemplo, os de Lingüística, Odontologia e de Química, desde 1971, o de Direito, desde 1973, o de Enfermagem, desde 1976, todos com precoce diálogo internacional, já que era no exterior que se buscava a expertise e a formação avançada para o fortalecimento do nascente sistema de pós-graduação brasileiro, mas nenhum deles com o impacto de visibilidade alcançado em período tão curto e tão precoce no contexto do ensino superior de Santa Catarina que apenas iniciava seus diálogos com o mundo acadêmico internacional.

Os avanços na capacidade de interação com qualidade no meio acadêmico internacional, principalmente o latino-americano do curso de pós-graduação em administração universitária levaram à criação, no ano de 1983, do Projeto Multinacional de Mestrado em Administração Universitária, em conjunto com a School of Education and Human Development da George Washington University (GWU), com o apoio da CAPES e da OEA, pelo qual passaram a ser enviados e recebidos professores e alunos brasileiros e norteamericanos para estadias de curta duração.

O projeto, incentivado pela CAPES, teve como base um acordo de cooperação entre a UFSC e a GWU e foi coordenado pelo professor Victor Meyer, gerando ainda a publicação de trabalhos conjuntos e o recebimento de bolsistas latino-americanos, principalmente do Peru, Uruguai, Chile e México, financiados pela OEA, “com passagens, auxílio instalação e bolsa de aproximadamente quinhentos dólares mensais" (MEYER, 2011) para cursarem todo o Mestrado na UFSC. O projeto retomou a organização de Seminários Internacionais, iniciado nos anos 1970, realizando em 1986 o Seminário Latino-Americano de Liderança e Administração Universitária e em 1989 o Seminário Internacional de Administração Universitária com representantes de 16 países dos continentes americano, europeu e asiático (VAHL, 2011; MEYER, 2011).

\footnotetext{
${ }^{8}$ UFSC, 2008
} 


\section{A INTERNACIONALIZAÇÃO DA UFSC MENSURADA PELOS RANKINGS INTERNACIONAIS}

Já no final do primeiro decênio dos anos 2000, com 10 de seus 57 programas de pósgraduação stricto sensu avaliados pela CAPES como "de caráter internacional", a UFSC havia integrado definitivamente a internacionalização à sua estratégia institucional. Seu crescimento em termos qualitativos e quantitativos e a crescente internalização por parte de seus tomadores de decisão sobre da necessidade de estruturá-la de forma a estar apta a implementar políticas institucionais objetivamente mais alinhadas com o preconizado pelas agências financiadoras da pesquisa e da pós graduação nacionais e internacionais bem como com a postura adotada pelas IES mais proeminentes no que se refere à produção de ciência e tecnologia, principalmente aquelas do Norte, com ampla supremacia nos rankings acadêmicos internacionais e portanto mais reconhecidas na escala de valores simbólicos da opinião acadêmica internacional, levou a inclusão definitivamente da internacionalização ao seu planejamento estratégico institucional, integrando-a em sua missão, visão e valores.

\subsection{O planejamento estratégico para a internacionalização}

Embora já discretamente apontada a intenção de solidariedade nacional e internacional em sua missão desde o ano de 1993, somente com o Plano de Desenvolvimento Institucional 2010 a 2014 (UFSC 2010), aparece explicitamente nos valores institucionais a intenção de firma-se no cenário acadêmico internacional como uma instituição de excelência, conforme veremos a seguir. Missão da UFSC:

produzir, sistematizar e socializar o saber filosófico, científico, artístico e tecnológico, ampliando e aprofundando a formação do ser humano para o exercício profissional, a reflexão crítica, solidariedade nacional e internacional, grifo nosso, na perspectiva da construção de uma sociedade justa e democrática e na defesa da qualidade de vida. (Missão aprovada pela Assembléia Estatuinte em 04/06/93 e incluída no Art. $3^{\circ}$ do Estatuto da UFSC).

Visão: Ser uma universidade de excelência.

Valores:

Afirmar-se, cada vez mais, como um centro de excelência acadêmica, no cenário regional, nacional e internacional (grifo nosso), contribuindo para a construção de uma sociedade justa e democrática e na defesa da qualidade da vida, com base nos seguintes valores: (i)Acadêmica e de Qualidade: Uma 
Instituição com busca contínua de patamares de excelência acadêmica, em todas as suas áreas de atuação, em especial no ensino, pesquisa e extensão; (ii) Ousada: Uma Instituição capaz de identificar e optar por novos caminhos e de criar novas oportunidades, carreiras e práticas em conformidade com uma visão inovadora; (iii)Culta: Uma Instituição criadora e irradiadora de arte e ciência; (iv) Atuante: Uma Instituição capaz de opinar, influenciar e propor soluções para grandes temas, tais como: acesso ao conhecimento e à cidadania, desenvolvimento científico e tecnológico, violência urbana, sustentabilidade ambiental e desigualdade social, entre outros; (v) Internacionalizada: Uma Instituição capaz de intensificar parcerias e convênios com instituições internacionais, contribuindo para o seu desenvolvimento, o do Brasil e o de outras nações (grifo nosso); (vi) Livre: Uma Instituição com servidores docentes e técnico-administrativos e estudantes livres para desenvolver suas convicções e suas vocações no ensino, na pesquisa e na extensão; (vii) Autônoma: Uma Instituição capaz de decidir sobre seus próprios rumos; (viii) Democrática e Plural: Uma Instituição que assegura o reconhecimento pleno de sua diversidade e autodeterminação de seus vários segmentos; (ix)Bem Administrada e Planejada: Uma Instituição com estratégias eficientes e efetivas de gestão e de busca dos recursos para a realização de suas metas; (x) Saudável: Uma Instituição saudável, ancorada na concepção de que a saúde é construída e vivida pelas pessoas em seu ambiente cotidiano, contribuindo para uma formação integral e maior qualidade de vida; (xi) Responsável: Uma Instituição orientada pela responsabilidade ética, social e ambiental (UFSC 2010b).

\subsection{A visão dos rankings acadêmicos internacionais}

Como instituição de pesquisa, a UFSC destaca-se entre as melhores universidades do País, posição sustentada pela titulação de seu corpo docente, qualidade de seus cursos de graduação e pós-graduação, qualificação dos servidores técnico-administrativos, volume de sua produção científica e forte relacionamento com empresas e arranjos produtivos da região e do país. O impacto dos seus investimentos em formação de quadros reflete-se na grande quantidade de publicações em revistas internacionais indexadas pelo ISI Web of Knowledge/Thomson ${ }^{9}$, que é uma plataforma de pesquisa para busca, mensuração e colaboração nas áreas de ciências exatas, ciências sociais, artes e humanidades, evidenciando uma produção científica altamente qualificada.

Todas as áreas do conhecimento estão representadas nas atividades de pesquisa realizadas na Instituição e encontram-se oficialmente cadastradas no Diretório de Grupos de

\footnotetext{
${ }^{9}$ Para o indicador ISI/Thomson, ver http://apps.isiknowledge.com
} 
Pesquisa do CNPq (UFSC, 2009). Essa excelência é materializada na qualidade dos seus programas de pós-graduação, dos quais três foram avaliados com o conceito sete e sete com o conceito seis pela avaliação trienal da CAPES 2007-2010, nos projetos obtidos por seus grupos de pesquisa, nos prêmios internacionais recebidos e nas inúmeras parcerias nacionais e internacionais nas quais estão envolvidos.

Há também participação de seus docentes em instâncias decisórias no País e do exterior, como, por exemplo, nos Comitês assessores do CNPq, da CAPES, do Programa Iberoamericano de Ciencia y Tecnologia para el Desarrollo (CYTED) e da Secretaria Nacional de Ciência, Tecnologia e Innovación (SENACYT), do Panamá, entre outros. Esse conjunto de dados a tornaram, no ano de 2008, a oitava instituição do Brasil com o maior número de equipes envolvidas no desenvolvimento científico e tecnológico nacional, tendo seus pesquisadores publicado 881 artigos em revistas científicas internacionais, colaborando ainda com o destaque da instituição no ranking Webometrics do ensino superior, no Scimago Institutions Ranking (SIR), que avalia o número de publicações, documentos citáveis e citações produzidas em uma IES e no ISI Web of Knowledge/Thomson.

Nesse sentido, observe-se que estar bem situado nos rankings acadêmicos internacionais passou a ser um valor, também nas universidades brasileiras. Mesmo não sendo objeto de análise específica nesse texto, avaliamos que, embora envolvidos em polêmicas e passíveis de serem vistos com cuidado ou por outra, apenas como indicadores para o mundo acadêmico, os rankings vêm sendo assimilados como importantes mecanismos de visibilidade das IES, num contexto onde a busca por torna-se uma universidade de "padrão internacional" parece estar sendo a tônica. Nesse contexto, a divulgação de uma boa posição nesses instrumentos de avaliação tem servido como um incentivo aos docentes e pesquisadores, resultando na atração de bons estudantes e de importantes parcerias internacionais, o que pode refletir-se num círculo virtuoso, incentivador e reflexo do processo de internacionalização acadêmica.

No que se refere a UFSC, embora não incluída nas classificações estabelecidas por dois dos principais rankings internacionais, o do Time Higher Education Supplement, THES que lista as 200 melhores instituições do mundo e o Academic Ranking of World Universities, ARWU, promovido pela Shanghai Jiao Tong University que lista as 500 melhores, ela passou a ser incluída a partir de 2009 na listagem das melhores universidades do Webometrics, que é

Rev. GUAL., Florianópolis, Edição especial 2011, p.208-226. 
o Ranking Mundial de Universidades na Web, publicado desde 2004, pelo Laboratório de Cibermetria $^{10}$ do Conselho Superior de Investigações Científicas (CSIC), que é uma agência estatal ligada ao Ministério de Ciência e Inovação da Espanha.

Esse instrumento é publicado duas vezes por ano, em janeiro e julho, usando indicadores cientométricos (número de trabalhos publicados e citações, relatórios e outros documentos com extensão pdf, ps, doc, ppt, nos últimos 10 anos) e baseado em diferentes aspectos da presença das instituições na web, tais como visibilidade, tamanho, produtividade e impacto.

Entre seus critérios estão incluídos indicadores de pesquisa e de qualidade de estudantes e docentes, além da visibilidade e o desempenho global da instituição medido pelos acessos, via internet, aos artigos por elas produzidos, o que acaba por penalizar a visibilidade internacional daquelas que não possuem sites em língua inglesa, a língua franca da $w e b$. Seus organizadores consideram a presença de uma instituição de ensino e pesquisa na web um indicativo de sua excelência e de seu comprometimento com a disseminação do saber, já que esta cobre não apenas a comunicação formal (revistas eletrônicas, repositórios), mas também informal, é mais barata mesmo mantendo altos níveis de qualidade associados aos processos de revisão por pares, podendo ainda potencialmente alcançar maiores audiências, oferecendo acesso ao conhecimento científico a pesquisadores e instituições de países em desenvolvimento além de terceiras partes (empresas, setores econômicos, sociais, culturais ou políticos) em suas próprias comunidades.

Esse ranking classificava as seis mil melhores instituições no plano mundial até 2009, sendo que em janeiro de 2010 aumentou esse número para oito mil e em julho do mesmo ano para 12 mil. Suas listagens se propõem a apresentar as melhores universidades do mundo, extraindo dessa relação as melhores por continente e por país, com suas respectivas classificações. Tendo em vista ser esse o indicador internacional em que mais fortemente aparecem as IES brasileiras e, portanto, pelo qual se pode, pelo menos no momento, ter uma visão panorâmica de sua posição frente às suas congêneres internacionais, optamos utilizá-lo para ter uma idéia dos resultados obtidos pela trajetória da UFSC nos últimos anos, sua posição no contexto mundial, mas principalmente no latino-americano e nacional.

\footnotetext{
${ }^{10} \mathrm{O}$ Laboratório de Cibermetria do CSIC se dedica à análise quantitativa na Internet e aos conteúdos da Rede, principalmente aqueles relacionados com o processo de geração e comunicação do conhecimento científico.
}

Rev. GUAL., Florianópolis, Edição especial 2011, p.208-226. 


\section{AS CONTINGÊNCIAS HISTÓRICAS E O ENSAIO PRECOCE DO QUE SE CONSOLIDARIA COMO O PROCESSO DE INTERNACIONALIZAÇÃO DA UFSC}

\section{Tabela 1}

Resumo da posição da UFSC nas últimas edições do Webometrics- 2009 a 2011

\begin{tabular}{cccccc}
\hline Data & $\begin{array}{c}\text { Posição } \\
\text { entre as IES } \\
\text { brasileiras }\end{array}$ & $\begin{array}{c}\text { Posição } \\
\text { entre as } \\
\text { IFES } \\
\text { brasileiras }\end{array}$ & $\begin{array}{c}\text { Posição } \\
\text { entre as IES } \\
\text { da América } \\
\text { Latina }\end{array}$ & $\begin{array}{c}\text { Posição no } \\
\text { ranking } \\
\text { mundial }\end{array}$ & $\begin{array}{c}\text { Número de } \\
\text { IES } \\
\text { avaliadas }\end{array}$ \\
Jan/2009 & $4^{\mathrm{a}}$ & $2^{\mathrm{a}}$ & $4^{\mathrm{a}}$ & $381^{\mathrm{a}}$ & 6.000 \\
$\mathrm{Julho} / 2009$ & $3^{\mathrm{a}}$ & $1^{\mathrm{a}}$ & $3^{\mathrm{a}}$ & $134^{\mathrm{a}}$ & 6.000 \\
$\mathrm{Jan} / 2010$ & $3^{\mathrm{a}}$ & $1^{\mathrm{a}}$ & $5^{\mathrm{a}}$ & $222^{\mathrm{a}}$ & 8.000 \\
$\mathrm{Julho} / 2010$ & $3^{\mathrm{a}}$ & $1^{\mathrm{a}}$ & $6^{\mathrm{a}}$ & $377^{\mathrm{a}}$ & 12.000 \\
Jan/2011 & $6^{\mathrm{a}}$ & $3^{\mathrm{a}}$ & $7^{\mathrm{a}}$ & $240^{\mathrm{a}}$ & 12.000 \\
Julho/2011 & $5^{\mathrm{a}}$ & $2^{\mathrm{a}}$ & $6^{\mathrm{a}}$ & $206^{\mathrm{a}}$ & 12.000 \\
\hline
\end{tabular}

Fonte: elaborado pela autora com base em dados do Webometrics. (http://www.webometrics.info)

Mesmo percebendo-se claramente o ranking como uma classificação com base em dados momentâneos, ou seja, a visibilidade avaliada na internet num dado período, pode estar sujeita a oscilações, podemos ter um quadro que nos balize sobre a posição da UFSC nos contextos internacional, latino-americano e nacional. Vinda da $304^{\mathrm{a}}$ posição em janeiro de 2009, passando para a $134^{\mathrm{a}}$ em julho daquele ano e caído para a $222^{\mathrm{a}}$ na edição de janeiro de 2010 e para $377^{\mathrm{a}}$ na edição de julho do mesmo ano, no que se refere às IES latino-americanas, ela se posicionava em 2010 como a primeira entre as universidades federais e a terceira no conjunto das instituições brasileiras. Já em julho de 2011, sobe para a $206^{a}$ classificação no âmbito mundial, para a sexta entre as latino-americanas e quinta melhor IES brasileira, só perdendo sua posição entre as federais brasileiras, caindo do primeiro para o segundo lugar.

Já em relação ao SIR, que avalia o número de publicações, documentos citáveis e citações, repetindo o que fazem o $A R W U$, o THES e o Webometrics, também elabora os seus rankings regionais. Dentre esses, o Ranking Ibero-Americano de Produção Científica e Internacional é uma ferramenta de análise e avaliação da atividade de pesquisa das IES na região e é elaborado sob a forma de um conjunto de rankings que apresenta, de forma ordenada, as atividades de pesquisa realizadas em um período.

Em sua edição de 2010, inclui todas as universidades ibero-americanas que produziram alguma comunicação científica durante o ano de 2008, analisando os dados de publicação e citação correspondentes ao período 2003-2008. Nele estão incluídas 607 universidades da região que publicaram algum documento recolhido pela base de dados Scopus em 2008, num total de 28 países que possuem pelo menos uma instituição no ranking,

Rev. GUAL., Florianópolis, Edição especial 2011, p.208-226. 


\section{AS CONTINGÊNCIAS HISTÓRICAS E O ENSAIO PRECOCE DO QUE SE CONSOLIDARIA COMO O PROCESSO DE INTERNACIONALIZAÇÃO DA UFSC}

numa distribuição assimétrica onde Espanha, Brasil e Colômbia representam cerca de $50 \%$ do total.

Tabela 2

Ranking Ibero-Americano de Produção Científica e Internacional 2010

\begin{tabular}{|c|c|c|c|c|c|c|c|}
\hline IBE & LAC & Instituição & País & $\begin{array}{l}\text { Produção } \\
\text { Científica }\end{array}$ & $\begin{array}{c}\text { Colaboração } \\
\text { internacional }\end{array}$ & $\begin{array}{c}\text { Media da } \\
\text { qualidade } \\
\text { científica*- } \\
\text { M.Q.C. }\end{array}$ & $\begin{array}{c}\text { Porcentagem } \\
\text { de } \\
\text { publicações } \\
\text { em revistas } \\
\text { reconhecidas }\end{array}$ \\
\hline 1 & 1 & USP & Brasil & 37952 & 24,81 & 0,81 & 40.35 \\
\hline 2 & 2 & $\begin{array}{c}\text { Un. } \\
\text { Autônoma } \\
\text { de México }\end{array}$ & México & 17.395 & 39,17 & 0,80 & 48,49 \\
\hline 3 & 3 & Unicamp & Brasil & 14,913 & 21,47 & 0,81 & 38,18 \\
\hline 4 & & $\begin{array}{c}\text { Universitá } \\
\text { de Barcelona }\end{array}$ & Espanha & 14,742 & 41,64 & 1,41 & 62,16 \\
\hline 5 & & $\begin{array}{c}\text { U. } \\
\text { Complutense } \\
\text { de Madrid }\end{array}$ & Espanha & 12.315 & 32,81 & 1,10 & 52,62 \\
\hline 6 & 4 & UNESP & Brasil & 12,270 & 16.8 & 0.63 & 31,37 \\
\hline 7 & 5 & UFRJ & Brasil & 12,133 & 26,67 & 0.80 & 39,01 \\
\hline 8 & & $\begin{array}{l}\text { U.Autónoma } \\
\text { de Barcelona }\end{array}$ & Espanha & 10.911 & 38,59 & 1,37 & 58,15 \\
\hline 9 & & U. Valencia & Espanha & 10.107 & 40,37 & 1,21 & 54,68 \\
\hline 10 & & $\begin{array}{c}\text { U. } \\
\text { Autónoma } \\
\text { de Madrid }\end{array}$ & Espanha & 9.755 & 40,21 & 1,27 & 59,69 \\
\hline 11 & 6 & $\begin{array}{l}\text { U. Buenos } \\
\text { Aires }\end{array}$ & Argentina & 9.741 & 39,13 & 0,94 & 51,06 \\
\hline 12 & & $\begin{array}{l}\text { Politécnica } \\
\text { Cataluña }\end{array}$ & Espanha & 9.631 & 37.67 & 1.20 & 37,34 \\
\hline 13 & 7 & UFRGS & Brasil & 8.971 & 25.35 & 0.82 & 39,94 \\
\hline 14 & & $\begin{array}{l}\text { U. Técnica } \\
\text { de Lisboa }\end{array}$ & Portugal & 8.815 & 43,54 & 1,20 & 46,27 \\
\hline 15 & & U. Porto & Portugal & 8.770 & 41,6 & 1,22 & 51,11 \\
\hline 16 & 8 & UFMG & Brasil & 8.107 & 24,56 & 0,81 & 37,82 \\
\hline 17 & & U. Granada & Espanha & 7.983 & 34,21 & 1,11 & 46,40 \\
\hline 18 & 9 & U. de Chile & Chile & 7.148 & 44,68 & 0,92 & 46,67 \\
\hline 19 & 10 & $\begin{array}{l}\text { U. Federal } \\
\text { SP }\end{array}$ & Brasil & 7.148 & 18,42 & 0,75 & 40,40 \\
\hline 20 & & $\begin{array}{l}\text { U. Santiago } \\
\text { Compostela }\end{array}$ & Espanha & 7.055 & 36,64 & 1,18 & 52,47 \\
\hline 33 & 14 & UFSC & Brasil & 4.460 & 24,04 & 0,77 & 32,53 \\
\hline
\end{tabular}

Rev. GUAL., Florianópolis, Edição especial 2011, p.208-226. 
Legenda: IBE $=$ países ibero-americanos

LAC $=$ países da América Latina e Caribe.

*A M.Q.C. permite comparar instituições com tamanhos e perfis diferentes, onde uma pontuação 0.80 significa que ela é citada $20 \%$ menos e 1.30 indica que é citada $30 \%$ mais que a média mundial.

Fonte: $\underline{\text { http://www.scimagoir.com/pdf/ranking_iberoamericano_2010.pdf }}$

Os dados desse ranking apresentam a Espanha e o Brasil em posição de destaque na produção de ciência na Ibero- América, por suas universidades estarem entre as 10 mais produtivas, onde cinco são espanholas, quatro brasileiras e uma mexicana. Nele a UFSC se posiciona em $8^{\circ}$ lugar entre as brasileiras e $14^{\circ}$ entre as latino-americanas.

\section{CONSIDERAÇÕES FINAIS}

Resta-nos apontar que, não obstante a priorização de distintos de indicadores de internacionalização de uma universidade pelos mais diversos organismos internacionais e aqueles adotados nacionalmente pela CAPES, responsável pela avaliação da pós-graduação no Brasil, esses, em sua maioria, são centrados na produção acadêmica em língua inglesa e em periódicos de impacto internacional, num exercício de homogeneização daquilo que não é homogêneo.

Mesmo não tendo sido objeto desse estudo, existem outros indicadores que podem e devem ser levados em conta por tais avaliações (SEBASTIAN, 2004; DE WIT, 2000; KNIHGT 1999, 2004, 2005) os quais certamente apontariam a relevância de uma abertura ao diálogo internacional e seus resultados computados no aumento de circulação internacional no campus em dimensões equivalentes aquela propiciada pelo envio de professores/ estudantes/pesquisadores para o exterior, do aumento dos acordos acadêmicos internacionais e da visibilidade institucional, entre outros indicadores de internacionalização.

Na UFSC dos anos 1960/1970, em que pesem as motivações de ordem políticoinstitucional e a ausência de dados numéricos que comprovem o vigor das atividades internacionais desenvolvidas, as contingências históricas foram estrategicamente aproveitadas em benefício de um incipiente, aos olhos de hoje, mas bastante precoce processo de internacionalização de uma IES fora do eixo mais dinâmico do país. 


\section{REFERENCIAS}

\section{ATCON, Rudolph. Rumos à Reformulação Estrutural da Universidade Brasileira.}

Brasília, MEC, 1966

ÁVERO, Maria de Lourdes. Da Universidade Modernizada à Universidade Disciplinada. São Paulo, Cortez/Autores Associados, 1991

CUNHA, Luiz Antônio. A Universidade reformada. Rio de Janeiro, Francisco Alves, 1988

De WIT. Changing Rationales for the Internationalization of Higher Education. In:

Internationalization of Higher Education: An Institutional Perspective. Papers on Higher Education. Bucharest, UNESCO/CEPES. 2000.

KNIGHT, Jane; de WIT, Hans (Ed.). Quality and Internationalisation in Higher

Education. Organization for Economic Cooperation and Development. Paris, France. 1999.

-------. Internationalization Remodelled: Definitions, Rationales and Approaches. Journal for Studies in International Education, $n .8$, v.1, pp. 5-31. Netherlands, 2004

An internationalization model: Responding to new realities and challenges. In De Wit et al. Internationalization of Higher Education in Latin America: The International Dimension. Washington DC. World Bank, v.1, 2005.

LAUS, S.P ; MOROSINI, M . L'internationalisation de l'enseignement supérieur au Brésil In: L'Enseignement Supérieur en Amérique Latine. La dimension Internationale. Washington DC. OCDE, 2005.

LIMA, João David Ferreira. UFSC: sonho e realidade. 2 ed. Florianópolis, UFSC, 2000

MEYER, Victor. Entrevista concedida a Sonia Pereira Laus. Florianópolis, jul. de 2011

NYE, Joseph S. Soft Power: The Means of Success in World Politics. New York, Public Affairs, 2004

OCDE. Avaliação das Políticas Educacionais de Educação: Estado de Santa Catarina. Série Reviews of National Polices for Education, 2010

OUI/IGLU; CRUB. Convênio que entre si celebram o Instituto de Gestão e Liderança Universitária da Organização Universitária Interamericana e o Conselho de Reitores das Universidades Brasileiras para a realização de Cursos de Especialização em Administração Universitária. Mimeo. 1983

OUI/IGLU; CRUB. Convênio que entre si celebram o Instituto de Gestão e Liderança Universitária da Organização Universitária Interamericana e o Conselho de reitores das 
Universidades Brasileiras para a realização de Cursos de Especialização em Administração Universitária. Mimeo. 1989.

ROMANELLI, Otaíza de Oliveira. História da Educação no Brasil (1930/1973). 20 ed. Vozes. Petrópolis, 1998

SEBASTIÁN, Jesus. Cooperación e Internacionalización de las Universidades. 1 ed. Buenos Aires: Biblos, 2004.

SILVA, Elizabeth Farias da. Ontogenia de uma Universidade: a Universidade Federal de Santa Catarina ( 1962-1980) 269 f. Tese( doutorado em educação). Universidade de São Paulo, São Paulo, 2000

UFSC. Anais do Seminário Internacional de Administração Universitária. Vol. II, Florianópolis, UFSC, 1971

UFSC. Departamento de Engenharia Mecânica da Universidade Federal de Santa Catarina: história e contribuições 1962-2008. Departamento de Engenharia Mecânica. EMC/UFSC, Florianópolis, 2008

UFSC. Diretório de Grupos de Pesquisa da UFSC - Censo 2008. UFSC, Florianópolis, 2009

UFSC. Plano de Desenvolvimento Institucional 2010 a 2014 / Universidade Federal de Santa Catarina. - Florianópolis: UFSC, 2010.

VAHL, Teodoro Rogério. Entrevista concedida a Sonia Pereira Laus. Florianópolis, jul. de 2011 


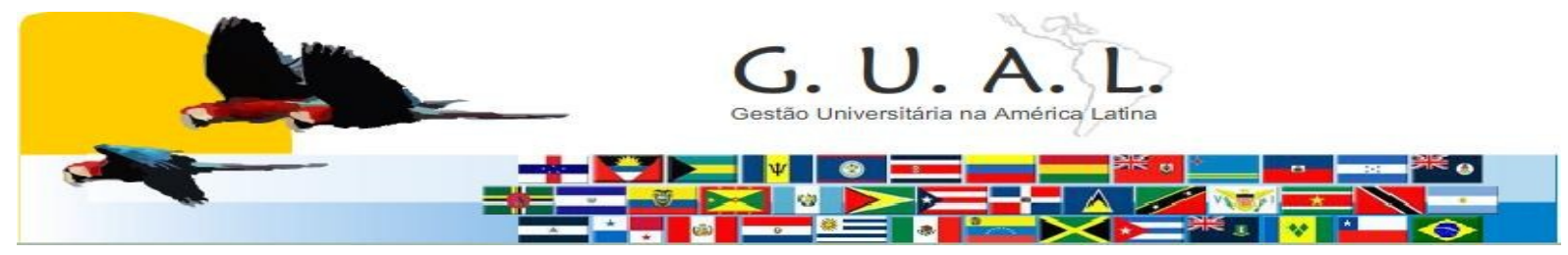

ISSN 1983-4535

\title{
THE HISTORICAL CONTINGENCIES AND TESTING EARLY AND THAT WOULD CONSOLIDATE THE PROCESS OF INTERNATIONALIZATION OF UFSC
}

\author{
Sonia Pereira Laus, Master \\ Universidade do Estado de Santa Catarina - UDESC \\ sonia.laus@udesc.br
}

\begin{abstract}
This article presents an overview of the internationalization process of the Federal University of Santa Catarina, focusing on activities developed during the 1960/1970 decade at University Administration postgraduate course in collaboration primarily with Latin American institutions and having a triggering factor agreement MEC/USAID. The study lists the main international academic rankings and its elements of evaluation, with emphasis on World Universities ranking on the Web - Webometrics and Ibero-American Science and International Production, highlighting the position of same UFSC, concluding with a critique of the indicators proposed by the homogenization now adopted by international organizations and by CAPES.
\end{abstract}

Keywords: Graduate studies. University. Internationalization. Academic rankings. 